\title{
HYPOPLASTIC ANAEMIA IN INFANCY AND CHILDHOOD: ERYTHROID HYPOPLASIA
}

\author{
BY \\ D. W. O'GORMAN HUGHES \\ From the Royal Alexandra Hospital for Children, Sydney, Australia
}

(RECEIVED FOR PUBLICATION JULY 7, 1960)

In 1936, Josephs reported 'a hypoplastic or aplastic type of anaemia confined to a failure of erythropoiesis' in two children. Diamond and Blackfan (1938) gave a more detailed description of the disorder in four children, and emphasized the features of a chronic progressive anaemia beginning early in infancy, with a tendency to moderate depression of the leucocyte and thrombocyte counts, and selective hypoplasia of the red cell precursors in the bone marrow. Several reports of this disease have appeared since (Rinvik, 1940; Kohlbry, 1941; Høyer, 1942; Rubell, 1942; Robson and Sweeney, 1948; Smith, 1949, 1953, 1959; Palmen and Vahlquist, 1950; Cathie, 1950; Lelong, Joseph, Polonowski, Desmonts and Colin, 1951; Anderson, 1952; Donnelly, 1953; Aldridge and Kidd, 1953; Kåss and Sundal, 1953; Verger and Leger, 1953; Fisher and Allen, 1953; Arrowsmith, Burris and Segaloff, 1953; Burgert, Kennedy and Pease, 1954; Diamond, 1954; Harper and Geikie, 1955; Calvert and Robson, 1956; Sundal, 1956; Pearson and Cone, 1957; Gasser, 1957), and a total of about 70 cases have been recorded. The reports have conformed to the original descriptions, with the exception that marrow examinations in some instances have revealed normal or increased numbers of normoblasts (Cathie, 1950). Various terms used to designate this haematological disorder include congenital hypoplastic anaemia, chronic hypoplastic anaemia (Josephs-Diamond-Blackfan type), erythrogenesis imperfecta, congenital pure red cell anaemia, chronic erythroblastopenia and pure red cell aplasia.

The aetiology is unknown, but is considered by many to rest in a congenital anomaly of the erythron, and the finding of associated congenital anomalies provides some support for this theory. The identification of anthranilic acid in the urine of some children with this disease suggested the presence of an inborn error of tryptophane metabolism; the administration of riboflavin to these patients resulted in a decrease in the excretion of anthranilic acid, but did not alter the haematological status (Altman and Miller, 1953). Smith (1949) reported the history of a child in whom anaemia developed in early infancy; the maternal antibody titre of anti:A was $1: 128,000$. It appears that isoimmunization may produce extreme and prolonged depression of the red cell precursors in infancy.

Erythroid hypoplasia, in more general terms, is of varied aetiology, and may occur at all ages. Acute hypoplasia may result from toxic, infective or allergic factors (Gasser, 1957), and sudden crises may develop in congenital spherocytosis (Owren, 1948), sickle cell anaemia (Chernoff and Josephson, 1951), and acquired haemolytic anaemia (Seip, 1955). Chronic forms of the disease have been attributed to chemical agents and autoimmune processes (Eisemann and Dameshek, 1954; Bonham Carter, Cathie and Gasser, 1954; Bousser, Christol, Dausset, Rampon, Jallut and Mery, 1955), and have been associated with the presence of thymic tumours. The subject of chronic erythroid hypoplasia in adults has been reviewed by Tsai and Levin (1957), but this report has included cases only where erythroid proportions were reduced in marrow examinations. Various forms of refractory anaemia with hypercellular bone marrow patterns have been described more recently by Dacie, Smith, White and Mollin (1959), and Vilter, Jarrold, Will, Mueller, Friedman and Hawkins (1960). In many instances the aetiology is unknown, and occasionally there have been reports, both in adults and children, of a familial incidence of the disease (Burgert et al., 1954; Diamond, 1954; Loeb, Moore and Dubach, 1953; Wallman, 1956).

For some time effective therapy of erythroid hypoplasia in infancy and childhood was restricted to the frequent administration of blood transfusions, though spontaneous remissions were known to occur. Three of 12 children cited by Diamond underwent spontaneous remission. From 1953 onwards, reports have been published concerning the successful use of corticotrophin and cortico- 
TA\&LE

ERYTHROID HYPOPLASIA: CLINICAL

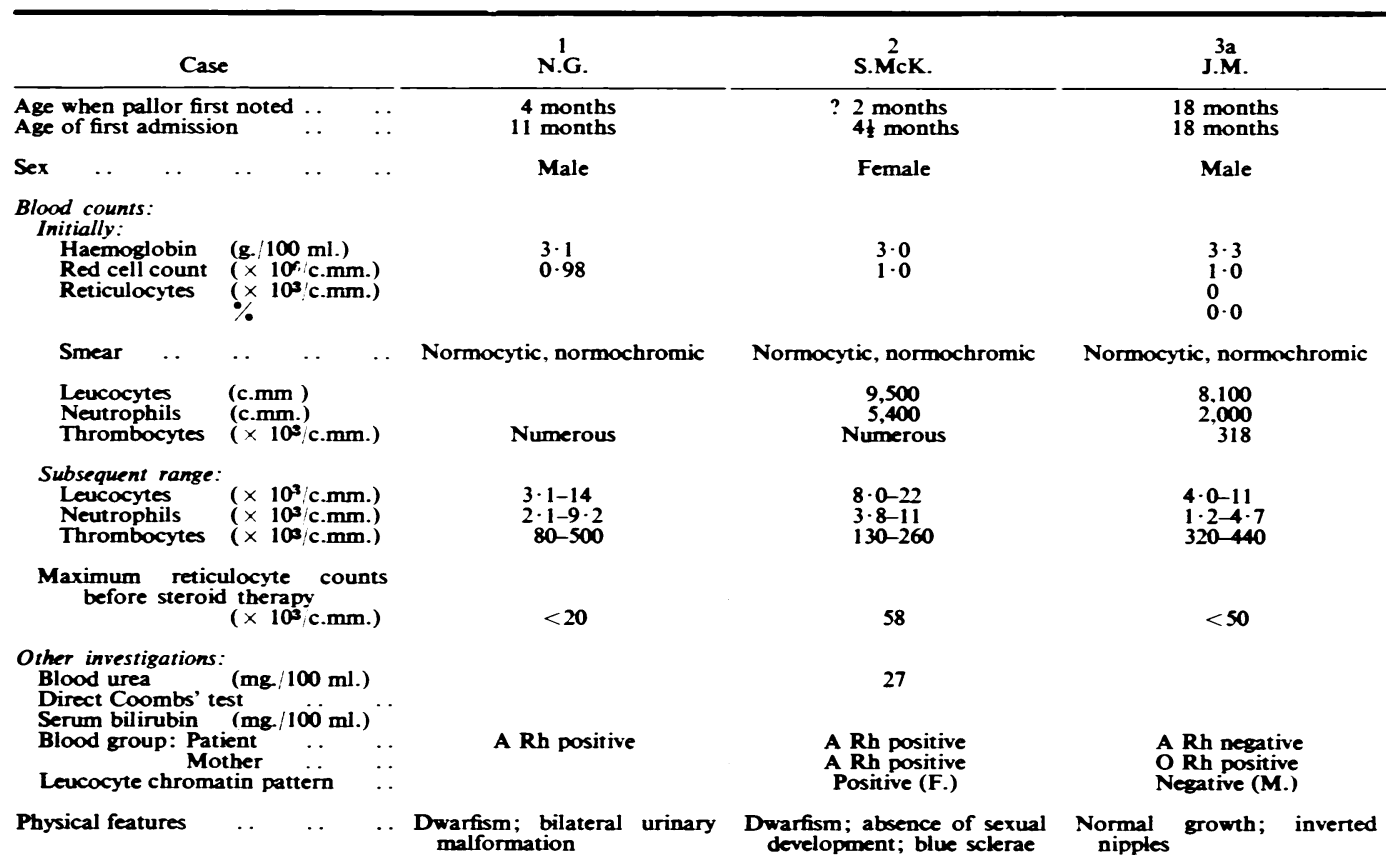

3a First admission to this hospital.

steroids in some patients, and these agents have now provided the mainstay of drug therapy in this disease. Arrowsmith et al. (1953) reported an unusual history of a child in whom megaloblastic erythropoiesis developed during steroid therapy, and normal erythropoiesis was obtained with the use of cortisone, folic acid and vitamin $\mathbf{B}_{12}$. After splenectomy, cortisone and vitamin $B_{12}$ therapy were required for some time to maintain a full haematological remission.

\section{Present Investigation}

The present series comprises eight patients with erythroid hypoplasia who developed anaemia within the first 18 months of life. All were admitted to the Royal Alexandra Hospital for Children, Sydney, between January 1953 and March 1960. The following criteria were required for inclusion in this report:

(1) A chronic aregenerative anaemia with relatively normal leucocyte and thrombocyte counts, appearing in the early months of life; (2) exclusion of cases if underlying systemic disease or postnatal 3b Relapse with megaloblastic features.

physico-chemical hazards were considered to be of major aetiological significance. Bone marrow studies were performed on all eight patients, usually by aspiration from the iliac crest or tibia, and occasionally by means of bone trephine. In all smears, no abnormality of the myeloid cells or megakaryocytes was detected. The term 'erythroid hypoplasia' was used to signify a failure of maturation of adequate numbers of erythroid marrow cells to reticulocytes and erythrocytes, "erythroblastic hypoplasia' being used more specifically to denote depression of the normoblasts to an arbitrary level of $10 \%$ or less of the total nucleated cells in the marrow. Defects in normoblastic maturation included multi-lobed and distorted nuclei, abnormal nuclear chromatin structure, scanty cytoplasm, and defective haemoglobinization of the nucleated red cells. Over the past three years, section of the clotted marrow specimen has been used as a guide to cellularity. With regard to earlier specimens, if it were considered that dilution with blood interfered with the correct interpretation, no comment concerning marrow cellularity was made. 
FEATURES AND LABORATORY FINDINGS

\begin{tabular}{|c|c|c|c|c|}
\hline G.J. & S.L. & K. $\stackrel{6}{W}$ & $\stackrel{7}{\text { D.McC. }}$ & $\stackrel{8}{\text { J.A. }}$ \\
\hline $\begin{array}{l}1 \text { month } \\
3 \text { months }\end{array}$ & 3 months & 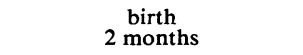 & $\begin{array}{l}2 \text { weeks } \\
5 \text { months }\end{array}$ & $\begin{array}{l}3 \text { months } \\
5 \text { months }\end{array}$ \\
\hline Male & Female & Female & Female & Female \\
\hline $\begin{array}{r}3 \cdot 7 \\
1 \cdot 3 \\
13 \\
<0 \cdot 5\end{array}$ & $\begin{array}{l}4 \cdot 5 \\
1 \cdot 3 \\
40 \\
3\end{array}$ & $\begin{array}{l}3 \cdot 9 \\
0 \cdot 98 \\
13 \\
<0 \cdot 5\end{array}$ & $\begin{array}{l}2 \cdot 5 \\
0 \cdot 7 \\
1 \\
<0 \cdot 5\end{array}$ & $3 \cdot 3$ \\
\hline Slight anisocytosis & Moderate anisocytosis & Moderate macrocytosis & Moderate macrocytosis & Normocytic, normochromic \\
\hline $\begin{array}{c}17,000 \\
5,600 \\
\text { Numerous }\end{array}$ & $\begin{array}{c}13,000 \\
4,200 \\
\text { Numerous }\end{array}$ & $\begin{array}{r}7,000 \\
4,000 \\
240\end{array}$ & $\begin{array}{r}11,000 \\
3,900 \\
210\end{array}$ & $\begin{array}{c}8,000 \\
6,300 \\
\text { Numerous }\end{array}$ \\
\hline $\begin{array}{l}5 \cdot 0-14 \\
1 \cdot 2-8 \cdot 7 \\
200\end{array}$ & $\begin{array}{c}7 \cdot 0-19 \\
2 \cdot 2-14 \\
300\end{array}$ & $\begin{array}{l}7 \cdot 0-10 \\
1 \cdot 7-6 \cdot 1 \\
\text { Numerous }\end{array}$ & $\begin{array}{l}8 \cdot 0-22 \\
2 \cdot 8-13 \\
190-760\end{array}$ & $\begin{array}{l}5 \cdot 0-8 \cdot 0 \\
1 \cdot 2-6 \cdot 3 \\
130-360\end{array}$ \\
\hline$<15$ & 53 & $<20$ & $<10$ & 30 \\
\hline $\begin{array}{c}\quad 34 \\
\text { Negative } \\
<0 \cdot 5 \\
\text { B Rh positive } \\
\text { AB Rh positive }\end{array}$ & $\begin{array}{c}36-52 \\
\text { Negative } \\
<0 \cdot 5 \\
\text { A Rh positive } \\
\text { O Rh positive } \\
\text { Positive (F.) }\end{array}$ & $\begin{array}{l}\quad 22 \\
<0 \cdot 5 \\
\text { A Rh positive } \\
\text { B Rh positive } \\
\text { Positive (F.) }\end{array}$ & $\begin{array}{c}22-44 \\
\text { Negative } \\
<0 \cdot 5 \\
\text { O } \mathrm{Rh} \text { positive } \\
\text { O } \mathrm{Rh} \text { positive }\end{array}$ & $\begin{array}{c}22 \\
\text { Negative } \\
<0 \cdot 5 \\
\text { A } R h \text { negative } \\
\text { A } R h \text { positive } \\
\text { Positive (F.) }\end{array}$ \\
\hline $\begin{array}{clc}\text { picanthic } & \text { folds; } & \text { widely } \\
\text { spaced } & \text { eyes; } & \text { normal } \\
\text { growth } & & \end{array}$ & 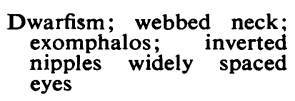 & $\begin{array}{l}\text { Small; epicanthic folds; } \\
\text { wide fontanelle; widely } \\
\text { spaced eyes; short neck }\end{array}$ & $\begin{array}{l}\text { Dwarfism; wide fontanelle; } \\
\text { blue sclerae }\end{array}$ & $\begin{array}{l}\text { Dwarfism; skeletal abnor- } \\
\text { mality; short neck; blue } \\
\text { sclerae; inverted nipples }\end{array}$ \\
\hline
\end{tabular}

The significant clinical laboratory features are listed in Table 1. Bone marrow findings are summarized in Table 2.

\section{Case Reports}

Case 1. N.G., a male infant, was born in June 1943. Pallor was noted from the age of 4 months, and when 8 months old he received his first blood transfusion. He was admitted to this hospital at the age of 11 months, when a severe aregenerative orthochromic anaemia was detected. The child received 120 blood transfusions, representing a total of 82 litres of blood, over the ensuing 10 years, and at no stage did signs of red cell regeneration appear. Stunted growth was a prominent feature. Pyuria was detected from the age of 5 years onwards. Bone marrow examinations in 1945 and 1949 revealed extreme depression of the red cell precursors. The child died of renal failure in 1954, at the age of $11 \frac{1}{2}$ years. Autopsy revealed extensive haemosiderosis, gross hepatosplenomegaly, bilateral double ureters, congenital bilateral hydronephrosis and pyelonephritis, and a moderately hypocellular bone marrow with marked depression of the erythroid elements. No abnormality of the myeloid or megakaryocyte elements was detected.

Comment: The presence of erythroid hypoplasia in infancy and the urinary malformations suggest a common congenital origin. The duration of the anaemia should exclude the possibilities of azotaemia and chronic infection as major aetiological factors.

Case 2. S.McK., a female infant, was born on July 23, 1947. Transient jaundice developed on the fourth day of life. At the age of $4 \frac{1}{2}$ months she was admitted to this hospital with a severe normocytic normochromic anaemia, and between 1947 and 1958 she received 32 blood transfusions at intervals varying between 33 and 402 days. Her progress was consistent with that of an aregenerative anaemia with periodic remissions; during relapse reticulocytopenia was constantly noted. In 1958 steroids were administered in large doses (up to $48 \mathrm{mg}$. of methylprednisolone daily) for three weeks without haematological improvement. A blood transfusion was administered and methylprednisolone therapy was continued in a dose of $8 \mathrm{mg}$. daily for six months and $4 \mathrm{mg}$. daily for eight months. In January 1960, the haemoglobin value was $15 \mathrm{~g}$. per $100 \mathrm{ml}$., and the child had not received a transfusion for 14 months. She was markedly dwarfed, her height being only $4 \mathrm{ft} .4$ in. at the age of $12 \frac{1}{2}$ years. Bone marrow studies were performed on several occasions: in June 1948, erythroblastic hypoplasia was noted; in October 1958 (before administering steroid therapy), the erythroid proportions were normal, and defective normoblastic maturation and 


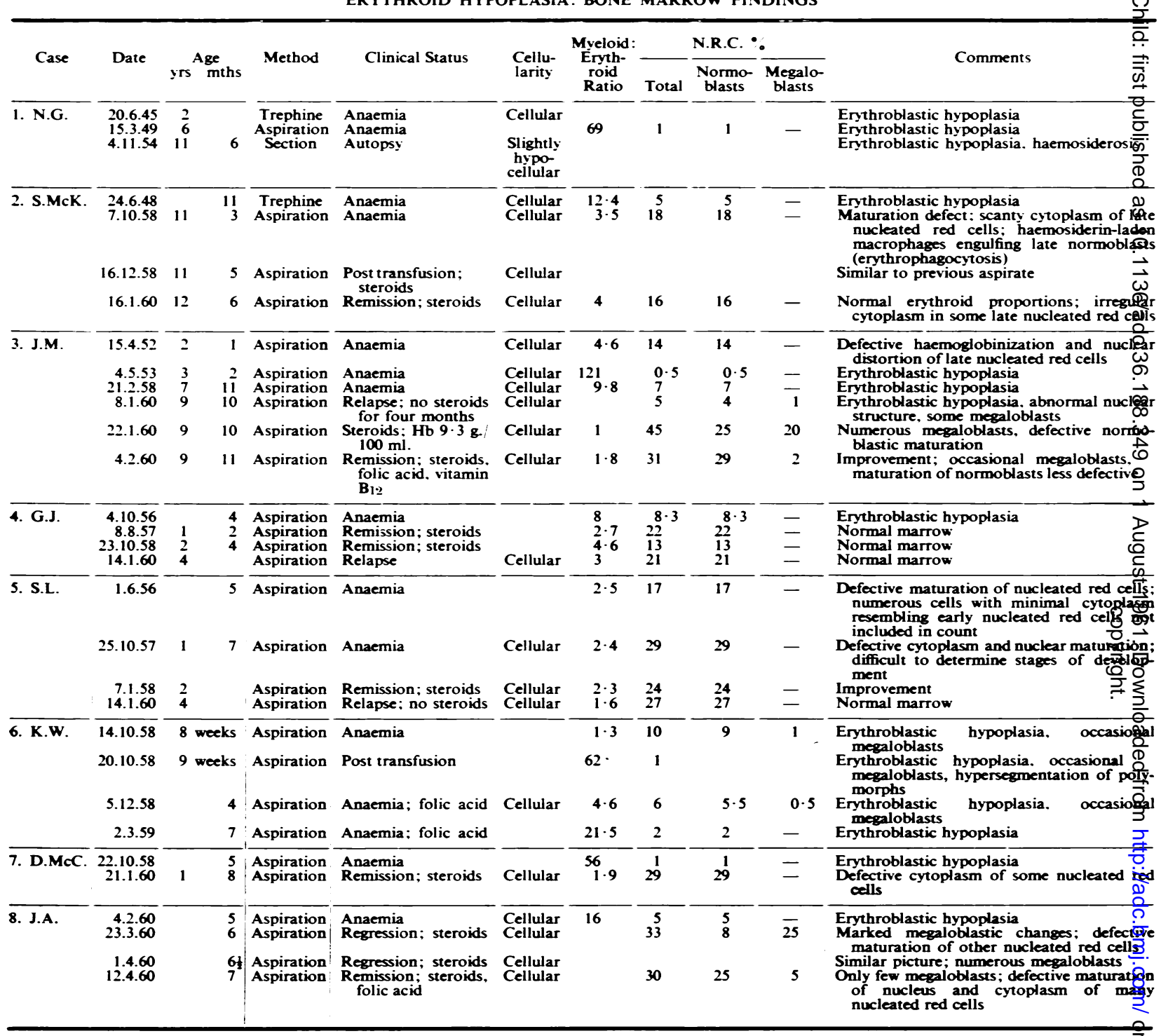

erythrophagocytosis were detected; in December 1958, the marrow picture was essentially similar to that of the previous aspirate; and in January 1960, minor defects were present in the cytoplasm of the late normoblasts.

Comment: The long intervals between transfusions indicated that spontaneous marrow regeneration sometimes occurred. The present remission is the longest the child has obtained, and may be related to the continuation of steroid therapy; the recent haemoglobin level of $15 \mathrm{~g}$. per $100 \mathrm{ml}$. is probably higher than would be expected if the marrow were producing red cells unaided. Erythrophagocytosis was detected in the marrow examination at one stage, suggesting the possibility of an immune or haemolytic process. However, there was no collateral clinical evidence to suggest the presence of haemolysis.

Case 3. (Fig. 1) J.M., a male, was born in March 1950. His progress was normal until the age of 18 months when a severe normocytic normochromic anaemia with reticulocytopenia developed. In the first $3 \frac{1}{1}$ years of life only two blood transfusions were adminis- 
tered, but blood transfusions were required subsequently for relief of an aregenerative anaemia on 25 occasions, at intervals of approximately three to four months. Bone marrow aspirations were performed on three occasions before the institution of steroid therapy. At the age of 2 years defective normoblastic maturation with normal erythroid proportions was noted, whilst at the age of 3 years erythroblastic hypoplasia alone was present, and at the age of 8 years erythroblastic hypoplasia was associated with defective maturation. Splenomegaly had been detected intermittently since 1954. In February 1958, prednisolone therapy was commenced in a dose of $40 \mathrm{mg}$. daily, and was accompanied by reticulocytosis and correction of the anaemia. The dose was reduced gradually and the drug was withdrawn 18 months later, at which stage mild anaemia was present. In January 1960 , the haemoglobin level was $8 \cdot 1 \mathrm{~g}$. per $100 \mathrm{ml}$., and reticulocytopenia was evident. Marrow examination revealed erythroblastic hypoplasia (Fig. 1), defective normoblastic maturation, and a small proportion of megaloblasts. Prednisolone $(20 \mathrm{mg}$. daily) was administered; marked reticulocytosis was apparent within a week, but no appreciable rise in the haemoglobin level occurred in the next fortnight, and marked macrocytosis was detected in the peripheral blood. A further bone marrow study at that stage demonstrated erythroblastic hyperplasia, the bizarre normoblasts and megalo- blasts being even more prominent than on the previous occasion. Additional folic acid and vitamin $\mathrm{B}_{12}$ therapy were administered, and the dose of steroids was increased for two days because of vomiting. The haemoglobin level increased in three days and rose by $3.7 \mathrm{~g}$. per $100 \mathrm{ml}$. over the ensuing fortnight; the reticulocyte count was usually raised, but was variable. Further marrow examinations two weeks after the commencement of combined therapy revealed improvement and a considerable reduction in the proportion of megaloblasts and abnormal erythroid elements. With reductions in the dose of prednisolone to $10 \mathrm{mg}$. daily the haemoglobin level fell, to rise again in one week when the dose was increased to $20 \mathrm{mg}$. daily. Tests performed in March 1960 , revealed no evidence of achlorhydria or malabsorption, and the Schilling test was normal. The child is now receiving $15 \mathrm{mg}$. prednisolone and $20 \mathrm{mg}$. folic acid daily. $\mathrm{He}$ is 10 years of age and is normal in physical development.

Comment: Anaemia was not apparent until the age of 18 months, but as long remissions obtained in the first $3 \frac{1}{2}$ years of life, it is possible that the defect of erythropoiesis was relatively minor in infancy, and became more marked in later childhood. He subsequently received numerous transfusions before steroid therapy was commenced at the age of 8 years, when rapid haematological response ensued. Relapse occurred when steroid therapy

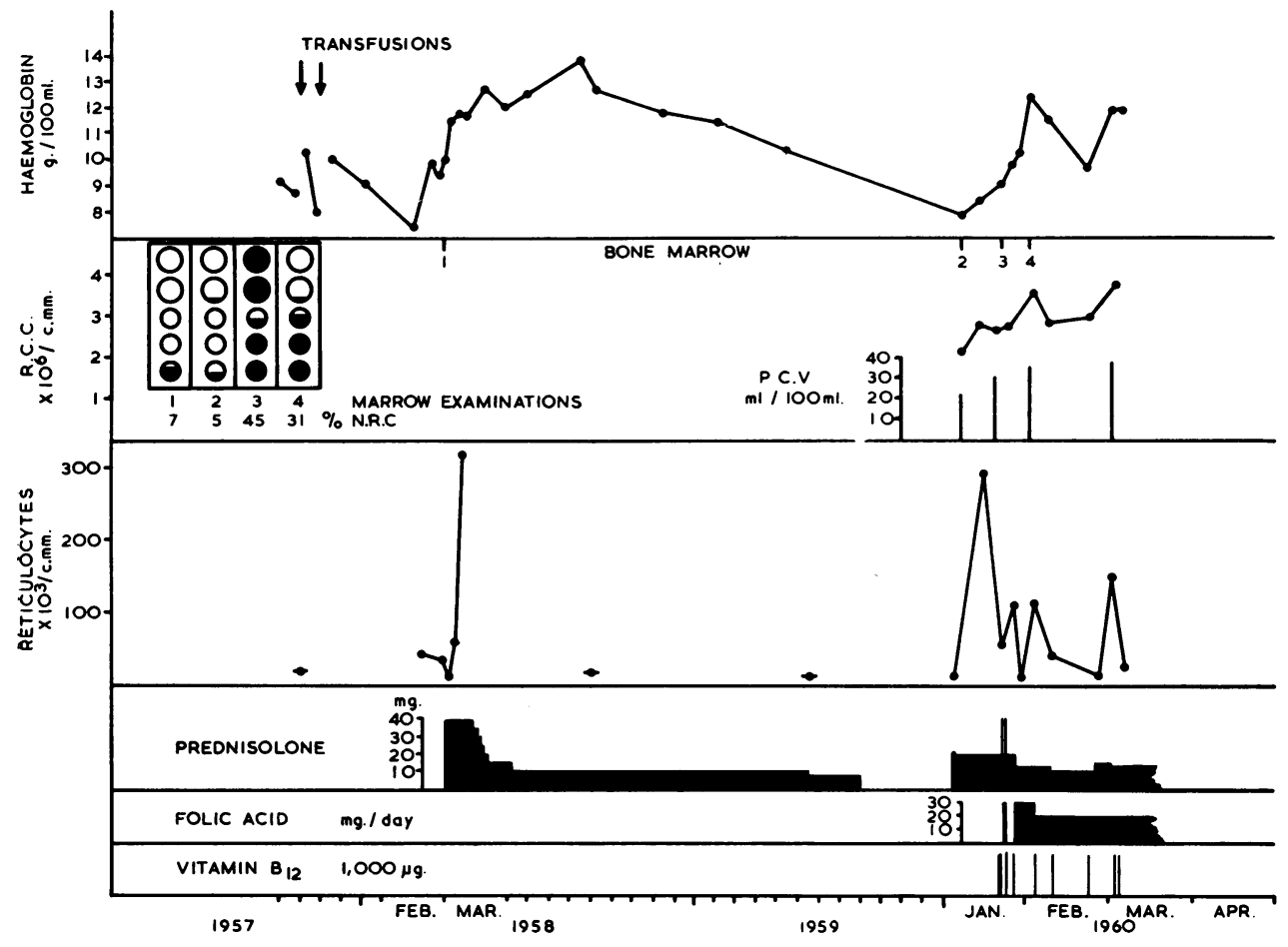

FIG. 1.-Progress of J.M. (Case 3) from the time of commencement of steroid therapy at the age of 8 years. Serial bone marrow findings (1-4) are illustrated by circles within the blocks. Each blackened circle represents $10 \%$ nucleated red cells; larger ones depict megaloblasts and smaller ones represent normoblasts. 


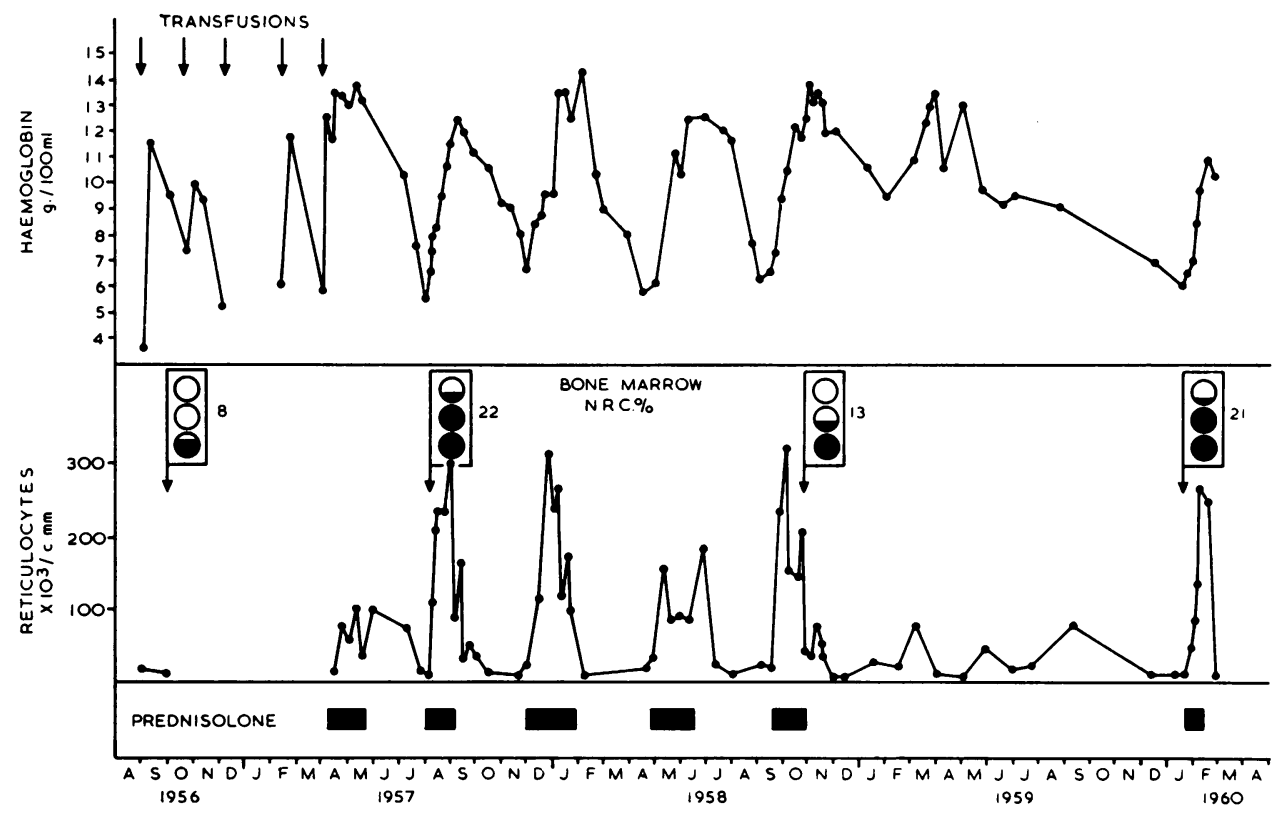

FIG. 2.-Progress of G.J. (Case 4). For legend see Fig. 1.

was withdrawn, and was associated with partial megaloblastic erythropoiesis, which became more obvious during subsequent steroid therapy. Combined vitamin $B_{12}$, folic acid, and steroid therapy was associated with correction of the anaemia and improvement in the marrow picture, suggesting that folic acid and vitamin $\mathbf{B}_{12}$ administration were partly responsible for the haematological remission.

Case 4. (Fig. 2) G.J., a male infant, was born on June 4, 1956. Increasing pallor was noted from the age of 1 month, and he was admitted to this hospital at the age of $12 \frac{1}{2}$ weeks with a severe orthochromic anaemia and reticulocytopenia. Blood transfusions were administered on five occasions at intervals of approximately two months, without evidence of red cell regeneration. After the last transfusion prednisolone was administered in initial doses of $25 \mathrm{mg}$. daily, and reticulocytosis and rise in haemoglobin levels appeared within a week. Steroid therapy was discontinued five weeks later. Recurrence of the anaemia with reticulocytopenia developed five times between August 1957 and January 1960, and on each occasion the administration of steroids was associated with correction of the anaemia. A satisfactory haemoglobin level was maintained without therapy for 12 months between September 1958 and September 1959. The initial marrow examination revealed erythroblastic hypoplasia, but subsequent studies during remission and relapse have shown a normal picture. The child is now $3 \frac{1}{2}$ years of age and is normal in mental and physical development. He has widely set eyes and prominent epicanthic folds.
Comment: On five occasions haematological remission occurred during steroid therapy, and the intervals between therapy are probably increasing. It is interesting to note that the last marrow picture during haematological relapse was entirely normal.

Case 5. (Fig. 3) S.L., a female infant of Greek parentage, was born on January 23, 1956. Exomphalos was present at birth, and required immediate surgery. At the age of 3 months the child was admitted to this hospital with a severe orthochromic anaemia; reticulocytosis was absent. Over the ensuing 21 months she received blood transfusions on 12 occasions for correction of an aregenerative anaemia. Transient pyuria was detected at the age of 8 months, and chemotherapy was administered with success. No renal abnormality was demonstrable by pyelography. The foetal haemoglobin concentration of the blood at the age of 5 months was $3.8 \%$. In November 1957 , prednisolone therapy was instituted, but it was not until $200 \mathrm{mg}$. of cortisone and later $60 \mathrm{mg}$. of prednisolone daily were administered that reticulocytosis and a rise in haemoglobin levels were detected. The dose of prednisolone was gradually reduced to $5 \mathrm{mg}$. daily over the succeeding six months, and therapy was withdrawn in October 1959. In January 1960, anaemia became apparent and the reinstitution of steroid therapy was followed by haematological remission. Bone marrow studies performed before the commencement of steroid therapy revealed normal or increased erythroid proportions and defective normoblastic maturation (Fig. 3). Subsequent examinations showed improvement, and in January 1960, the marrow appearances were normal when the child was in 


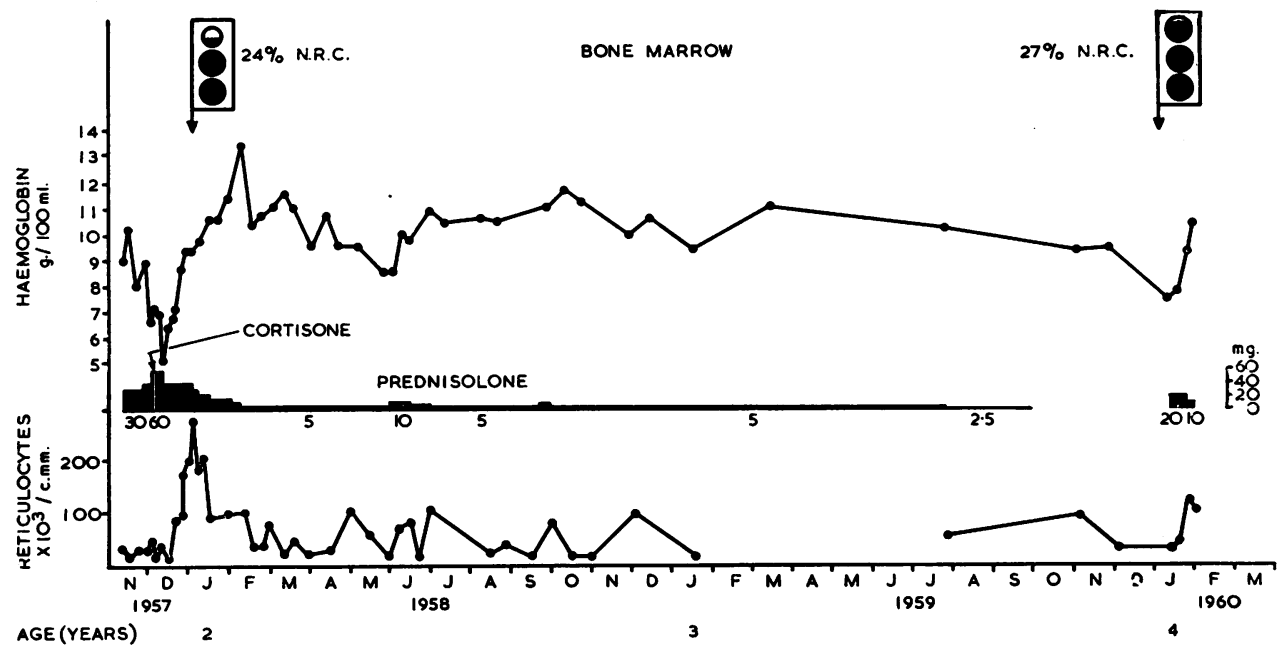

Fig. 3.-Progress of S.L. (Case 5) from time of commencement of steroid therapy.

haematological relapse. She is now 4 years old and is markedly stunted in growth and underweight. She has widely-spaced eyes, a flat nose, receding chin, webbed neck, and inverted nipples. The leucocyte chromatin pattern is positive.

Comment: The presence of exomphalos, webbed neck and dwarfism provides supportive evidence of a congenital origin of the anaemia. High doses of steroids were required to induce haematological remission, although smaller amounts were adequate for maintenance therapy. The marrow picture was normal while the child was in haematological relapse.

Case 6. (Fig. 4) K.W., a female infant, was born on August 22, 1958. Pallor was present at birth and became more marked subsequently. At the age of $7 \frac{1}{2}$ weeks, she was admitted to this hospital, where investigations revealed a severe anaemia, moderate macrocytosis,

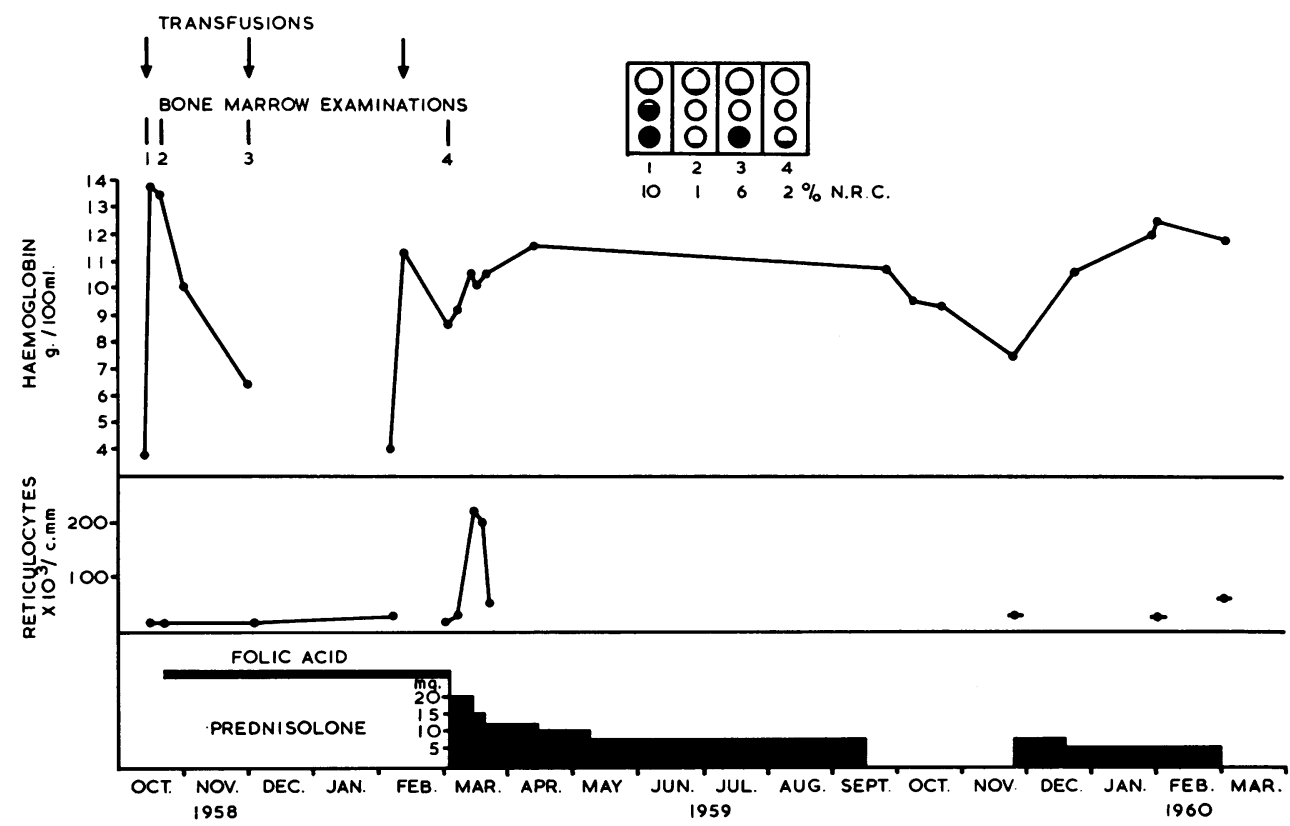

Fig. 4.-Progress of K.W. (Case 6). Each blackened circle represents $5 \%$ nucleated red cells in the marrow. Larger circles depict megaloblasts. 
and reticulocytopenia. Marrow studies revealed erythroblastic hypoplasia and the presence of occasional megaloblasts. Blood transfusions were administered on three occasions at intervals of two months. Folic acid was administered for a period of six months without evidence of haematological improvement; megaloblasts did not disappear from the marrow smears for several months, but were not evident just before the commencement of steroid therapy. On March 2, 1959, folic acid therapy was withdrawn and steroid therapy was commenced. Reticulocytosis and a rise in haemoglobin level were noted nine days later, and satisfactory haemoglobin values were maintained on small doses of prednisolone, which was withdrawn in September 1959. Within two months anaemia and reticulocytopenia became apparent; prednisolone therapy was recommenced in a dose of $7.5 \mathrm{mg}$. daily and the haemoglobin value rose. At the age of 17 months, the child was of slightly less than average weight and height. She had a snub nose, widely-spaced eyes, prominent epicanthic folds and a moderately widely patent fontanelle.

Comment: Anaemia was probably present at birth and progressed slowly. Marrow examinations revealed erythroblastic hypoplasia and associated megaloblastic changes which did not disappear for many months despite a prolonged course of folic acid therapy, but were not apparent at the stage when steroid therapy was commenced. The anaemia was corrected following steroid administration and recurred when the drug was withheld.

Case 7. (Fig. 5) D.McC., a female infant, was born on May 18, 1958. Mild jaundice occurred in the first few days of life; pallor was noted at the age of 2 weeks, and became progressive. At the age of 5 months she was admitted to this hospital, where investigations revealed a severe anaemia, moderate macrocytosis and reticulocytopenia. Pyuria was detected shortly afterwards, and chemotherapy was successfully prescribed. Bone marrow examinations revealed erythroblastic hypoplasia. After the administration of blood transfusions, prednisolone was given in relatively small quantities $(7.5 \mathrm{mg}$. daily). Moderate anaemia with fluctuating reticulocyte counts was present over the next few months; in January 1959, the dose of prednisolone was increased to $10 \mathrm{mg}$. daily, and the haemoglobin reached a satisfactory level after several months. The dose of prednisolone was reduced to $2.5 \mathrm{mg}$. daily in May 1959, but by October anaemia had become marked. An increase in the dose of steroids was followed by correction of the anaemia. At the age of 20 months the child was well, but was less than the tenth centile in height and weight for her age. Blue sclerae and a moderately widely patent fontanelle were noted. The spleen was just palpable. Marrow studies at that stage revealed normal proportions of red cell precursors, some of which showed imperfect haemoglobinization.

Comment: When relatively small amounts of prednisolone $(7.5$ to $5 \mathrm{mg}$. daily) were used initially, no impressive rise in haemoglobin values occurred. An increase in dosage was followed by correction of the anaemia over a period of several months. Relapse occurred when only $2.5 \mathrm{mg}$. of prednisolone were administered daily, and remission followed the institution of larger doses. Evidence for small stature was present before steroids were administered.

Case 8. (Fig. 6) J.A., a female infant, was born on August 29, 1959. Pallor was noted at the age of $3 \frac{1}{2}$ months and she received a blood transfusion in January

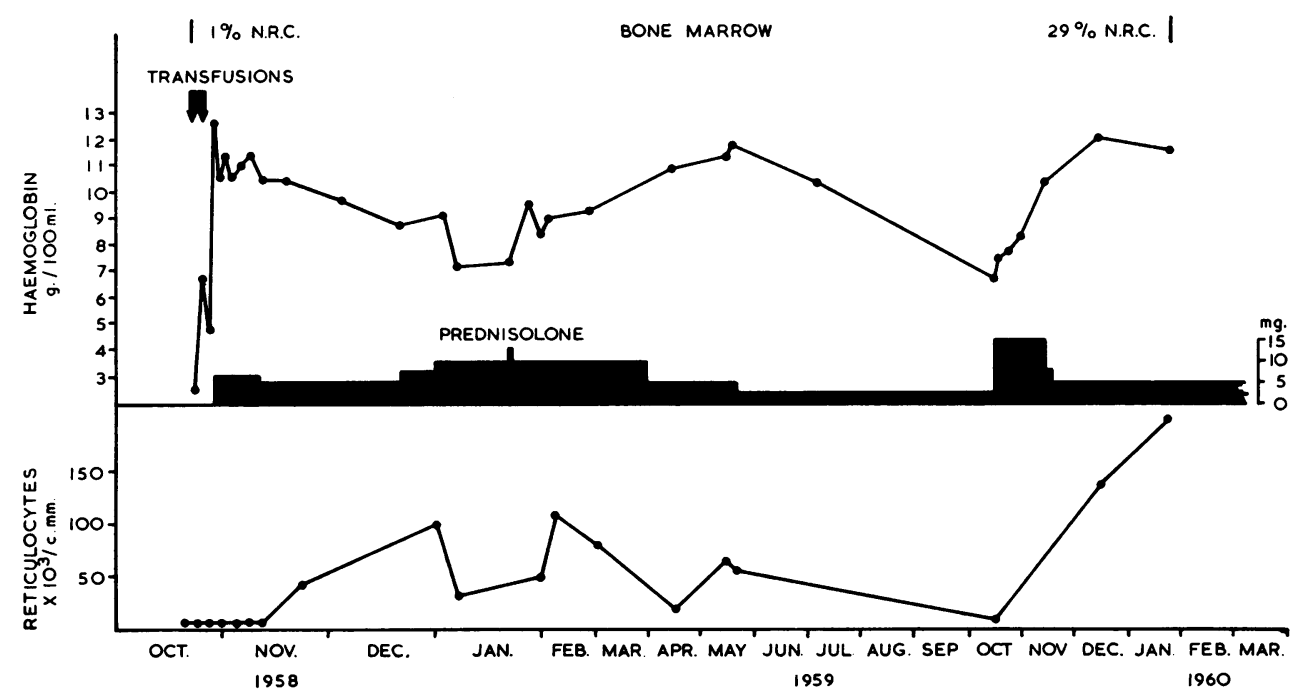

Fig. 5.-Progress of D.McC. (Case 7). 


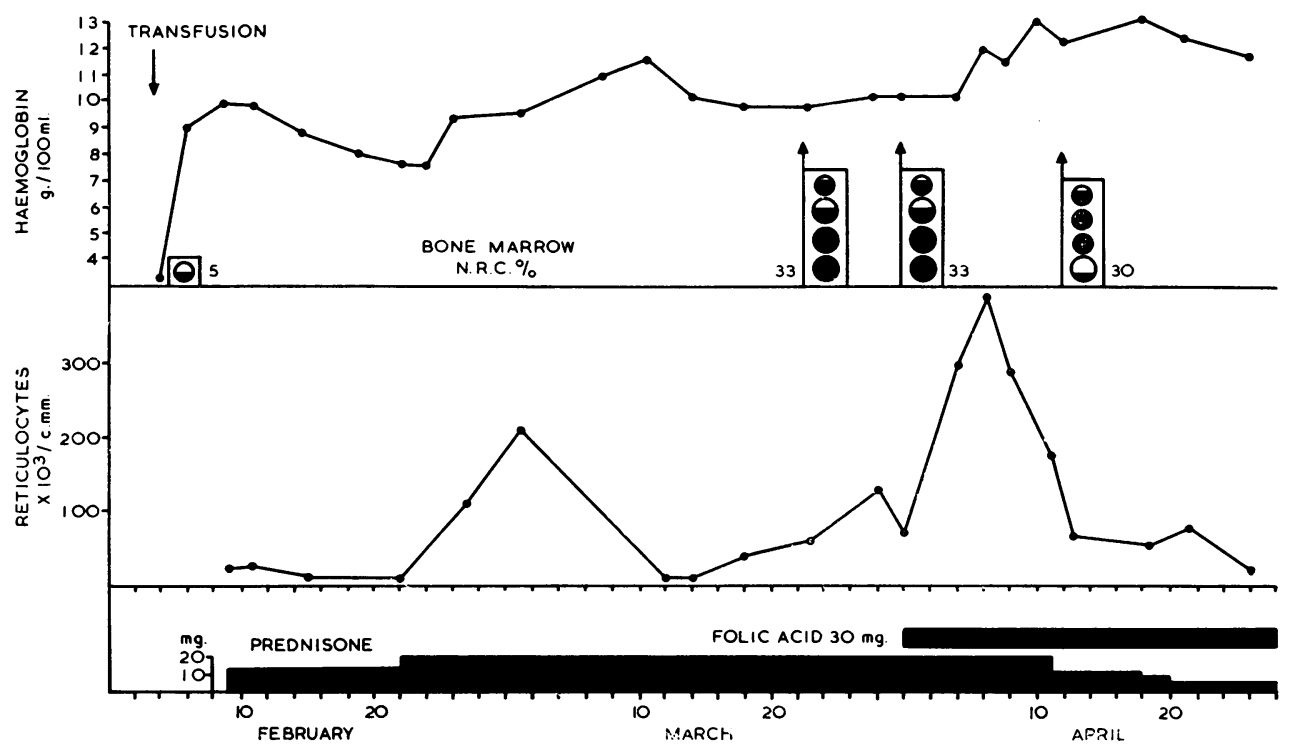

Fig. 6.-Progress of J.A. (Case 8). For legerd see Fig. 1.

1960. Her feedings had consisted of a powdered milk mixture. She was transferred from the country to this hospital on February 4, at the age of $5 \frac{1}{2}$ months, when severe normocytic normochromic anaemia was detected. Marrow examination revealed erythroblastic hypoplasia. From the day of admission for a period of three weeks mild diarrhoea was present. After the administration of a blood transfusion on February 4, prednisone was given in a dose of $15 \mathrm{mg}$. daily without haematological response; after three weeks of therapy the dose was increased to $20 \mathrm{mg}$. daily, and within four days reticulocytosis and a rise in haemoglobin values occurred, which continued for three weeks. The haemoglobin level subsequently fell, and reticulocytopenia was noted frequently. Marrow studies on two occasions demonstrated predominantly megaloblastic erythropoiesis with defective normoblastic maturation. Folic acid $(30 \mathrm{mg}$. laily) was administered in addition to prednisone; a secondary reticulocytosis and rise in haemoglobin values occurred within a few days and continued while the dose of steroids was maintained. Marrow studies after 10 days of combined therapy revealed considerable improvement. Megaloblasts were present in only small proportions, but defects in normoblastic maturation were still evident. Hepatomegaly was present during the period of observation, splenomegaly being noted only in the initial stages of hospitalization. The child was considerably dwarfed, and weighed only $10 \mathrm{lb}$. at the age of $7 \frac{1}{2}$ months. Physical features included short limbs, a short thick neck, and blue sclerae, her appearance resembling that of a child with achondroplasia. However, radiological examination revealed features consistent with a congenital defect of osseous development, but were not typical of any particular form of osteo- chondrodystrophy. Biochemical tests demonstrated no evidence of metabolic bone disease.

Comment: The presence of dwarfism and skeletal anomalies suggests that the anaemia is congenital in origin. There is no reason to suspect that the osseous abnormality is affecting red cell production. Steroid therapy was associated with temporary haematological response when the dose was increased, but regression followed, and marrow examinations revealed megaloblastic erythropoiesis. The administration of folic acid was associated with haematological remission and an improvement in the marrow picture. It is possible that the diarrhoea contributed to the folic acid deficiency.

\section{Discussion}

Clinical Features. All eight patients presented with severe anaemia at ages varying from 8 weeks to 18 months. Five were female and three were male. Most of the infants had been well previously, apart from progressive pallor, which was noted in the first month of life in three patients. Gastrointestirial symptoms were common when the anaemia became profound. Hepatosplenomegaly was present in three patients (Cases 1, 3 and 8), two of whom (Cases 1 and 3) had received numerous transfusions. Splenomegaly alone was noted at some stage of the disease in two other patients (Cases 6 and 7). The size of the spleen varied, and was not related to the haematological status of the patient. Various physical anomalies were noted in this series, of which the commonest was dwarfism (considerably less 
than the tenth centile for age in height and weight) in five patients. Three of these five children had additional major anomalies, which included gross urinary tract malformations, exomphalos and a webbed neck, and a generalized skeletal abnormality. Additional features, of doubtful significance, were prominent epicanthic folds in two children, a wide fontanelle in two, blue sclerae in three, and inverted nipples in three children.

Aetiology. It was not possible to attribute the anaemia to any extrinsic factors either before or after birth. Only one mother (of Case 6) had any recognizable illness during pregnancy (hyperemesis, toxaemia, and a moderate antepartum haemorrhage) or was exposed to any unusual physico-chemical hazards (chest radiograph at six weeks' gestation; administration of chlorotriazide and reserpine in the last month of pregnancy). No history of any blood disorders in the families was obtainable. The blood groups of the mothers and patients are included in Table 1 ; it is extremely unlikely that isoimmunization was related to red cell depression in five of these infants (Cases 2, 4, 6, 7 and 8). The associated physical anomalies and the onset of anaemia early in life provide supportive evidence that the disturbance of erythropoiesis is congenital. Although cases have been reported (Burgert et al., 1954; Kåss and Sundal, 1953; Rubell, 1942; Diamond and Blackfan, 1938) with associated neutropenia or thrombocytopenia, suggesting superficial resemblance to Fanconi's pancytopenia with multiple skeletal defects, erythroid hypoplasia appears to be a distinct entity. Steroid therapy has not proved to be an effective form of therapy in Fanconi's anaemia, whilst in erythroid hypoplasia of infancy the haematological response is often dramatic. There is a tendency to spontaneous remission in recorded cases with increasing age, and it is possible that the elaboration of sex hormones may be responsible. The benefit occasionally derived from splenectomy in childhood (Case 7 of Heaton, Crosby and Cohen, 1957), and in adult life (Loeb et al., 1953) may be evidence of a further hormonal factor affecting erythropoiesis. Radiological examination of the chest failed to reveal the presence of a thymic tumour in any patient in the present series.

Peripheral Blood Picture. The most prominent haematological findings were profound anaemia and absence of reticulocytosis. In seven patients the haemoglobin value on the first admission to this hospital was less than $4 \mathrm{~g}$. per $100 \mathrm{ml}$. The red cells were usually of normal morphology, although moderate macrocytosis was noted in some infants. Reticulocyte counts of 50,000 cells per c.mm. or less were present in the five patients in whom these were performed initially, and in all patients reticulocytopenia was demonstrated at subsequent examinations. Neutrophil counts were occasionally at the lower limit of normal in three children (Cases 3, 4 and 8 ), and thrombocyte counts were moderately reduced at some stage in three patients (Cases 1, 2 and 8). Macrocytosis and reticulocytosis were seen during steroid therapy; however, macrocytosis was not marked in one patient (Case 8) whose marrow demonstrated profound megaloblastic erythropoiesis.

Bone Marrow Studies. The bone marrow studies showed considerable variation. Before the use of steroid therapy, the following findings were noted: erythroblastic hypoplasia alone in four patients (Cases 1, 4, 7 and 8); erythroblastic hypoplasia with associated megaloblastic changes in one (Case 6); variable combinations of erythroblastic hypoplasia, normal erythroid proportions, and defective normoblastic maturation in two (Cases 2 and 3); and normal or increased erythroid proportions with defects of normoblastic maturation in one child (Case 5). Progress marrow studies were performed during steroid therapy in six patients (Cases 2, 3, 4, 5,7 and 8). Improvement in the marrow picture was noted in four patients (maturation defect less marked in Cases 2 and 5; minor defect in Case 7; normal marrow in Case 4), but in two children (Cases 3 and 8) megaloblastic erythropoiesis and defective normoblastic maturation were detected in the early stages of steroid therapy; these abnormalities were much less prominent two weeks after the additional administration of folic acid or vitamin $\mathbf{B}_{12}$. The bone marrow of three children was examined when haematological relapse occurred following the cessation of steroid administration; in two patients (Cases 4 and 5) the picture was normal, and in one child (Case 3) bizarre normoblasts and occasional megaloblasts were detected in the smears.

Despite these variable features, some pattern emerged during the study of progress marrow examinations. When erythroblastic hypoplasia was present, the morphology of the red cell precursors was usually normal; when erythroid proportions were normal or increased, defects of maturation became apparent, and were usually most marked at the late normoblast stage. The marrow picture improved after the administration of steroids, except in two instances where active erythropoiesis appeared to unmask a latent deficiency of folic 
acid or vitamin $\mathbf{B}_{12}$. The administration of these latter agents with steroids was associated with haematological improvement.

Other Laboratory Investigations. Blood urea levels showed transient elevation in two patients (Cases 5 and 7); the results are not available for Case 1. Pyuria was detected in three children (Cases 1, 5 and 7) and was transient in two (Cases 5 and 7$)$; the duration of the anaemia excluded the possibilities of chronic azotaemia or infection as major aetiological factors. The direct Coombs' test was negative and the serum bilirubin level was within normal limits in all patients where these tests were performed (see Table 1). A thymic tumour was not detected in the radiological examination of the chest in any patients.

Course and Therapy. Before the advent of steroid therapy, the only consistent benefit in these patients was derived from repeated blood transfusions. Spontaneous remissions occurred in two children (Cases 2 and 3) for periods as long as 14 months. Three patients in this series received more than 25 blood tranfusions, and the remainder at least two. The only child who died (Case 1) received 82 litres of blood, and was found to have extensive haemosiderosis at autopsy.

Steroid therapy was administered to seven patients, and was associated with haematological improvement in all. In one (Case 2), intensive therapy for three weeks failed to induce haematological improvement, and a transfusion was administered. Steroid administration was continued subsequently and she has remained in haematological remission for over 14 months. As spontaneous remissions had occurred previously for periods as long as 14 months, it is possible that her present satisfactory state may be unrelated to steroid therapy. Of the other six patients, none has required transfusions since the time when steroids were first administered, representing intervals of $25,37,29,13,18$ and two and a half months. There is no doubt that steroid therapy was effective, as haematological remission occurred on five occasions in one child (Case 4), and in other patients (Cases 3, 5, 6 and 7) haematological relapse developed when the drug was withdrawn or reduced in dose, to be followed by remission with the reinstitution of adequate therapy. In general, amounts equivalent to 20-30 $\mathrm{mg}$. of prednisolone daily were sufficient to initiate increased red cell production, and such a response was usually evident within four to 11 days. In two patients (Cases 5 and 8 ) reticulocytosis and a rise in haemoglobin levels did not appear until the dose was increased, when signs of red cell regeneration became apparent in four to five days. The nature of this response suggests that the adjustment of steroid dosage may be critical, although one cannot exclude the possibility that this form of therapy may be required for several weeks to induce effective erythropoiesis.

Numerous megaloblasts were noted in marrow examinations of two children (Cases 3 and 8) during steroid therapy, and reversion to normoblastic erythropoiesis followed the additional administration of folic acid and vitamin $\mathbf{B}_{12}$. In one (Case 8), megaloblastic erythropoiesis was very marked, and a well-defined haematological response followed the use of folic acid. In the other patient (Case 3), megaloblastic erythropoiesis was present to a lesser degree, and haematological improvement after the administration of vitamin $B_{12}$, folic acid and prednisolone was less dramatic; moreover, the daily dose of prednisolone administered during the critical period was considerably smaller than that used to induce the first remission two years earlier. The progress of J.A. (Case 8) is similar to that of the child described by Arrowsmith et al. (1953). When a suboptimal haematological response follows an adequate trial of steroid therapy, it seems advisable to perform further marrow examination to exclude the possibility of megaloblastic erythropoiesis; in Case 8 there was little evidence of macrocytosis in the peripheral blood picture.

Maintenance steroid therapy was usually effective when amounts equivalent to 5-10 mg. of prednisolone were administered daily, and was associated with no harmful side-effects. Relapse occurred within a few weeks or months in five patients (Cases 3, 4, 5, 6 and 7) when the drug was withdrawn or drastically reduced in dosage, so that prolonged maintenance therapy or intermittent therapy was required. It is likely that the intervals between relapse will become longer with increasing age, as suggested by the progress of Case 4 . The longest period of observation of a patient with steroid administration is three years (Case 4).

It has been suggested (Gasser, 1957; Smith, 1959) that steroid therapy is of little avail when transfusion haemosiderosis has developed. Only one of the present group of patients could be considered unduly refractory to treatment (Case 2), although only two patients (Cases 2 and 3 ) had received many blood transfusions before steroid therapy was tried.

A variety of therapeutic regimes was adopted for patients in this series. It is suggested that blood transfusions be administered on the initial two or three occasions when anaemia develops. In doing so, it should be possible to assess the nature of the 
disease and the intervals between transfusions which may be required. Moreover, haematological remissions may occur for long periods, as illustrated in Cases 2 and 3. Steroid therapy may be instituted subsequently, and it is convenient to continue maintenance treatment for a period of six to 12 months, at the end of which time the patient's requirements may be judged according to haematological progress. High doses of steroids may be required for several weeks to induce haematological remission, and the reason for therapeutic failures in other case reports may be in the administration of inadequate initial doses of steroids. Suboptimal haematological response during steroid therapy should prompt investigation into the possibility of megaloblastic erythropoiesis.

\section{Summary}

The literature concerning erythroid hypoplasia in infancy and childhood is reviewed briefly, and the details of eight further patients are presented.

All children developed a severe aregenerative anaemia at ages varying between 8 weeks and 18 months. A high incidence of associated physical anomalies was noted in this series, and included dwarfism, urinary tract malformations, exomphalos, skeletal abnormalities and webbed neck. The association of these anomalies with the onset of anaemia early in life provides supportive evidence that the aetiology of the anaemia rests in a congenital defect of the erythron.

Bone marrow studies revealed considerable variation. Erythroid elements were present in decreased, normal or increased proportions, and defects of normoblastic maturation were noted at some stage in several patients. During steroid therapy the marrow picture showed improvement in four patients, but megaloblastic erythropoiesis became prominent in two other children, and haematological improvement followed the additional administration of folic acid or vitamin $B_{12}$.

One patient died; the remainder are still living. Spontaneous remission for long periods occurred in two patients before the advent of steroid therapy. Steroids were administered to seven children, of whom six received definite, and one possible benefit.

High doses of steroids for several weeks may be required to induce haematological remission; suboptimal responses to adequate therapy should suggest the possibility of megaloblastic erythropoiesis.

A method of management of these patients is kriefly outlined.

I wish to express my gratitude to Dr. R. D. K. Reye for his suggestions and interpretation of the bone marrow slides; to Professor Lorimer Dods for his advice and encouragement; to Drs. S. E. L. Stening, M. L. Edwards, S. E. J. Robertson and J. Alexander for their encouragement and permission to publish the case histories; to my colleagues and members of the Department of Pathology.

\section{REFERENCES}

Aldridge, A. G. V. and Kidd, P. (1953). Correspondence. Brit. med. J., 1, 729.

Altman, K.' I. and Miller, G. (1953). A disturbance of tryptophan metabolism in congenital hypoplastic anaemia. Nature (Lond.), 172,868 .

Anderson, D. E. (1952). Chronic aregenerative anaemia of the newborn. Med. J. Aust., 1, 573.

Arrowsmith, W. R., Burris, M. B. and Segaloff, A. (1953). Production of megaloblastic marrow by administration of cortisone in aplastic anemia, with subsequent response to vitamin B.12 $42,778$.

Bonham Carter, R. E., Cathie, I. A. B. and Gasser, C. (1954). Aplastische Anämie (chronische Erythroblastophthise) bedingt durch Autoimmunisierung. Schweiz. med. Wschr., 84, 1114.

Bousser, J., Christol, D. Dausset, J., Rampon, S., Jallut, H. and Mery, J. P. (1955). Épisode érythroblastopénique prolongé ayant marqué le début d'une anémie hémolytique chronique avec auto-anticorps. Sang, 26, 804.

Burgert, O. Jr., Kennedy, R. L. J. and Pease, G. L. (1954). Congenital hypoplastic anemia. Pediatrics, 13, 218.

Calvert, R. J. and Robson. T. (1956). Cortisone therapy in erythrogenesis imperfecta. Arch. Dis. Childh., 31, 177.

Cathie, I. A. B. (1950). Erythrogenesis imperfecta. Ibid., 25, 313.

Chernoff, A. I. and Josephson, A. M. (1951). Acute erythroblastopenia in sickle-cell anemia and infectious mononucleosis. A.M.A. Amer. J. Dis. Child., 82, 310 .

Dacie, J. V., Smith, M. D., White, J. C. and Mollin, D. L. (1959). Refractory normoblastic anaemia: a clinical and haematological study of seven cases. Brit.J. Haemat., 5, 56.

Diamond, L. K. (1954). Editorial comment, Year Book of Pediatrics, 1954-1955 series, p. 308. Year Book Publishers, Chicago. and Blackfan, K. D. (1938). Hypoplastic anemia. Amer. J. Dis. Child., 56, 464.

Donnelly, M. (1953). A case of t rimary red cell aplasia. Brit. n.ed. J., 1, 438.

Eisemann, G. and Dameshek, W. (1954). Splenectomy for 'pure red-cell' hypoplastic (aregenerative) anemia associated with autoimmune hemolytic disease. (Report of a case.) New Engl. J. Med., 251, 1044.

Fisher, O. D. and Allen, F. M. B. (1953). Erythrogenesis imperfecta or congenital hypoplastic anaemia (Diamond-Blackfan type). Arch. Dis. Childh., 28, 363 .

Gasser, C. (1957). Aplasia of erythropoiesis. Pediat. Clin. N. Amer., May, 1957, p. 445.

Harper, M. and Geikie, G. (1955). Congenital pure red cell anaemia or erythrogenesis imperfecta. Med. J. Aust., 2, 245.

Heaton, L. D., Crosby, W. H. and Cohen, A. (1957). Splenectomy in the treatment of hypoplasia of the bone marrow, with a report of twelve cases. Ann. Surg., 146, 637.

Høyer, K. (1942). Aregenerative, probably congenital, anaemia in an infant with deficiency of erythroblasts in the bone marrow. Nord. med., 14, 1097.

Josephs, H. W. (1936). A naemia of infancy and early childhood. Medicine (Baltimore), 15, 307.

Kåss, A. and Sundal, A. (1953). Anaemia hypoplastica congenita (anaemia typus Josephs-Diamond-Blackfan). Report of a case treated with adrenocorticotropin with effect. Acta paediat. (Uppsala), 42, 265.

Kohlbry, C. O. (1941). Congenital hypoplastic anemia. Case

report. J. Pediat., 19, 662. (1951). L'anémie chronique avec arrêt de la maturation normoblastique (type Blackfan-Diamond). Arch. frans. Pédiat., $8,473$.

Loeb, V., Jr., Moore, C. V. and Dubach, R. (1953). The physiologic evaluation and management of chronic bone marrow failure. Amer. J. Med., 15, 499.

Owren, P. A. (1948). Congenital hemolytic jaundice. The pathogenesis of the 'hemolytic crisis'. Blood, 3, 231.

Palmen, K. and Vahlquist, B. (1950). Stationary hypoplastic anemia. Acta haemat. (Basel), 4, 273.

Pearson, H. A. and Cone, T. E., Jr. (1957). Congenital hypoplastic anemia. Pediatrics, 19, 192.

Rinvik, R. (1940). Two cases of idiopathic hypoplastic anemia in infants. Acta paediat. (Uppsala), 28, 304.

Robson, T. and Sweeney, P. J. (1948). Chronic hypoplastic anaemia arising in infancy. Arch. Dis. Childh., 23, 294. Rubell, I. (1942). Hypoplastic congenital anemia. J. Pediat., 
Seip, M. (1955). Aplastic crisis in a case of immuno-hemolytic anemia. Acta med. scand., 153, 137.

Smith, C. H. (1949). Chronic congenital aregenerative anemia (pure red-cell anemia) associated with iso-immunization by the blood group factor 'A'. Blood, 4, 697

(1953). Hypoplastic and aplastic anemias of infancy and childhood: with a consideration of the syndrome of nonhemolytic anemia of the newborn. J. Pediat., 43, 457.

(1959). Pure red-cell anemia. Ibid , 54, 609.

Sundal, A. (1956). Anemia hypoplastica congenita treated with cortisone. Correction of the anemia with cortisone treatment during 4 years. Acta paediat. (Uppsala), 45, 456.
Tsai, S. Y. and Levin, W. C. (1957). Chronic erythrocytic hypoplasia in adults. Amer. J. Med., 22, 322.

Verger and Leger (1953). Anémie hypoplastique de la première enfance (anémie de Blackfan-Diamond). Arch. franç. Pédiat., $10,328$.

Vilter, R. W., Jarrold, T., Will, J. J., Mueller, J. F., Friedman, B. I. and Hawkins, V. R. (1960). Refractory anemia with hyperand Hawkins, V. R. (1960), Refr
plastic bone marrow. Blood, 15, 1 .

Wallman. I. S. (1956). Hereditary red cell aplasia. Med. J. Aust. 2, 488. 